\title{
Sensory and Communicative Sciences
}

National Cancer Institute

\section{Source}

National Cancer Institute. Sensory and Communicative Sciences. NCI Thesaurus. Code C19028.

Basic, applied, and clinical research in the auditory and vestibular systems, the visual system, speech/language, and the sensory systems concerned with smell, touch and taste. 